\title{
EDUCATEC - REFLEXÕES E PROPOSTAS DE USO DAS FERRAMENTAS TECNOLÓGICAS DIGITAIS NA EDUCAÇÃO
}

\author{
Marina Siqueira David ${ }^{1}$, Talita da Silva Ernesto ${ }^{2 *}$ \& Milena Ferreira Hygino Nunes ${ }^{3}$
}

\begin{abstract}
RESUMO
DAVID, M.S; ERNESTO, T.S.; NUNES, M.F.H. EDUCATEC- Reflexões e Propostas de Uso das Feramentas Tecnológicas Digitais na Edcação. Perpectivas Online: Humanas \& Sociais Aplicadas, v.7, n.19, p.48-52, 2017.

Este trabalho tem como objetivo apresentar os resultados parciais, de julho de 2016 a março de 2017, do projeto de pesquisa EDUCATEC, que iniciou pela necessidade de se repensar a forma de ensinar, em um mundo cada vez mais dominado pela cibercultura, com alunos nativos digitais. Com abordagem qualitativa, o projeto tem

digitais no processo de ensino-aprendizagem, por meio de aulas práticas no laboratório de informática do ISECENSA, fóruns de discussão teórica e prática, atividades pedagógicas elaboradas e praticadas pelas próprias participantes do projeto, em seus ambientes de atuação profissional.
\end{abstract} permitido, de forma satisfatória, a capacitação das participantes para o uso de recursos tecnológicos

Palavras-chave: Ferramentas tecnológicas digitais; Tecnologia na Educação; Práticas pedagógicas; Ensinoaprendizagem. 


\begin{abstract}
This paper intends to present the partial results, from July 2016 to March 2017, of the EDUCATEC research project, which began with the need to rethink a way of teaching, in a world increasingly dominated by cyberculture, with native digital students. With a qualitative

in the teaching-learning process, process, through practical classes in ISECENSA's computer lab, forums for theoretical and practical discussion, and pedagogical activities elaborated and practiced by the Project participants in their professional settings.
\end{abstract} approach, the project has enabled, satisfactorily, participants to use digital technological resources

Keywords: Digital technology tools; Technology in Education; Pedagogical practices; Teaching-learning.

\footnotetext{
${ }^{1}$ Acadêmica de Pedagogia ISECENSA- Institutos Superiores de Ensino do CENSA - ISECENSA - Rua Salvador Correa, 139, Centro, Campos dos Goytacazes, RJ, CEP: 28035-310, Brasil;

${ }^{2}$ Institutos Superiores de Ensino do CENSA - ISECENSA - Laboratório de Novas Tecnologias- Rua Salvador Correa, 139, Centro, Campos dos Goytacazes, RJ, CEP: 28035-310, Brasil;

${ }^{3}$ Institutos Superiores de Ensino do CENSA - ISECENSA - Rua Salvador Correa, 139, Centro, Campos dos Goytacazes, RJ, CEP: 28035-310, Brasil.

(*)e-mail: talitaernesto@gmail.com

Data de chegada: 19/04/2017 Aceito para publicação: 09/06/2017
}

Persp. online: hum. \& sociais aplicada., Campos dos Goytacazes, 19 (7), 48-53, 2017

seer.perspectivasonline.com.br 


\section{INTRODUÇÃO}

Atualmente, quando se fala em "Tecnologia na Educação", dificilmente se pensa em giz e quadronegro ou mesmo em livros e revistas. Normalmente, quando se usa o termo TIC's (Tecnologias de Informação e Comunicação), a atenção se concentra no computador, que se tornou o ponto de convergência de todas as tecnologias mais recentes. $\mathrm{O}$ uso dos computadores, nas mais diferentes mídias, é praticamente universal. Convive-se com elementos multimídia há muito tempo, mesmo sem que se dê conta disso.

E os professores, como estão? Qual é a conduta deles em sala de aula? Perante alunos "nativos digitais" (conceito cunhado pelo educador e pesquisador Marc Prensky, em 2001, para descrever a geração de jovens nascidos a partir da disponibilidade de informações rápidas e acessíveis na grande rede de computadores - a Web), os professores precisam sair de sua "zona" de conforto e entender os meios que o aproximem de seus alunos. Portanto, precisam de atualização e constante aprendizado.

É neste cenário de rápidas transformações que se situa o pensamento contemporâneo, possuidor de uma pluralidade de perfis e tendências que correspondem aos tipos de racionalidade atualmente vigentes em nossa sociedade. Essa pluralidade de perfis e tendências e o contexto sócio-econômico global redefinem a finalidade e relevância da escola, da educação.

Vivemos em uma sociedade da informação que só se converte em uma verdadeira sociedade do conhecimento para alguns, aqueles que puderam ter acesso às capacidades que permitem desentranhar e ordenar essa informação (POZO, 2003).

Em seu legado, Paulo Freire (2002, p. 29) foi bastante perspicaz ao incitar que "[...] não há ensino sem pesquisa e pesquisa sem ensino". A docência, em todas as suas fases (ensinos fundamental, médio, superior), exige pesquisa, planejamento, estratégias de ensino e atuação efetiva do professor como mediador do processo de ensino-aprendizagem, estimulando o aluno à construção do conhecimento. "Ensinar não é transferir conhecimento, mas criar as possibilidades para a sua própria produção ou a sua construção" (FREIRE, 2002, p. 47).

Confirma-se, então, a necessidade de se repensar a forma de ensinar (qualquer que seja a disciplina), porque o mundo é outro, como visto anteriormente, e os alunos, nativos digitais, também. Esta é a colaboração que o projeto de pesquisa Educatec quer produzir localmente. Para isso, objetiva-se:

- Capacitar os participantes para o uso das ferramentas tecnológicas digitais no processo de ensinoaprendizagem;

- Colaborar para a superação das dificuldades existentes quanto ao uso dos recursos tecnológicos no processo de ensino-aprendizagem;

- Promover inovações pedagógicas instrumentalizadas pelos recursos tecnológicos já disponibilizados nas escolas em que atuam;

- Ampliar a capacidade de compreensão do mundo dos participantes, por meio das reflexões teóricas acerca das necessidades da sociedade do conhecimento;

- Estimular mudança de mentalidade dos participantes, a fim de sejam protagonistas de práticas inovadoras em sua atuação profissional.

\section{METODOLOGIA}

No projeto em questão, a metodologia utilizada tem abordagem qualitativa de pesquisa, sendo desenvolvida da seguinte forma:

O projeto desenvolve, concomitantemente, fóruns de discussão presenciais, com o intuito de refletir e debater sobre o uso das novas tecnologias no processo de ensino-aprendizagem, disponibilizando um referencial teórico e prático (elaborado na forma de oficinas, abordando as práticas pedagógicas mediadas pelas TIC com vistas à reflexão e ao desenvolvimento das principais habilidades, de acordo com a realidade das participantes).

O projeto atende a 12 alunas do curso de Pedagogia do ISECENSA, que demonstraram interesse em participar quando apresentamos a proposta do EDUCATEC às turmas do curso de Pedagogia. De acordo

Persp. online: hum. \& sociais aplicada., Campos dos Goytacazes, 19 (7), 48-53, 2017

seer.perspectivasonline.com.br 
com Sampieri (2013), é fundamental a coleta de dados na pesquisa qualitativa. Para responder aos objetivos por nós elaborados neste projeto, utilizamos o instrumento questionário com escala Likert.

\section{DESENVOLVIMENTO}

No desenvolvimento do projeto fizemos a construção científica sobre os assuntos tratados, intercalando com apresentação de recursos tecnológicos digitais. Iniciamos com o Google Drive, pois é uma ferramenta que facilita a produção de artigos, passando por Padlet, Socrative, Prezi, Redes Sociais Digitais (Instagram, Facebook, Twitter), Khan Academy, QR Code, Cam Scanner, FlipBoard. Nosso trabalho foi baseado em ferramentas tecnológicas que podem ajudar na hora de elaborar atividades e aulas, tanto para crianças quanto para adolescentes e adultos. Durante os encontros, frisamos a importância de colocar esse conhecimento em prática de forma consciente.

Foi proposta a elaboração de atividades pedagógicas, utilizando obrigatoriamente tecnologias, para que seja confirmado um efetivo aproveitamento das reflexões feitas no grupo de pesquisa e nas oficinas, ao saber explorar os recursos tecnológicos disponíveis na prática pedagógica, mesmo que de forma adaptada.

Percebemos, por meio das respostas do questionário aplicado e da nossa vivência nos encontros do projeto, que os objetivos inicialmente propostos têm sido alcançados, como detalhamos a seguir:

$\mathrm{Na}$ afirmação "Consigo diminuir a distância entre nativos e imigrantes digitais, uma vez que estou empoderada do ambiente digital", $70 \%$ disseram que concordam e $10 \%$ disseram que concordam totalmente, mostrando que há, dentre a maioria das alunas, a consolidação de conceitos-chave sobre o universo das TIC na Educação, resultando na utilização de recursos tecnológicos. Esse empoderamento ocorre não só no âmbito teórico, na aquisição de conceitos, mas também no prático, quando $50 \%$ das alunas concordam e $30 \%$ concordam totalmente que conheceram, no projeto, softwares que favorecem a aprendizagem significativa, em suas diversas formas. Vemos, aqui, o cumprimento dos objetivos de capacitação das participantes para o uso das ferramentas tecnológicas digitais no processo de ensino-aprendizagem e a superação das dificuldades existentes quanto ao uso dos recursos tecnológicos nesse processo.

Esse empoderamento traz não só os benefícios acima citados, mas também, e de maneira mais profunda, o estímulo à mudança de mentalidade das participantes. Isso se confirma quando $60 \%$ afirmam que concordam totalmente e $30 \%$ afirmam que concordam que, apesar de não dominarem todas as ferramentas ensinadas, superaram a visão limitada do uso da tecnologia em sala de aula como recurso pedagógico. Essa mudança de mentalidade promove o protagonismo das alunas participantes de práticas inovadoras em sua atuação profissional. Isso é evidenciado quando $60 \%$ e $20 \%$ disseram concordar e concordar totalmente, respectivamente, que passaram a utilizar em sua prática pedagógica algumas ferramentas aprendidas nos encontros do Educatec. Vemos, aqui, o cumprimento dos objetivos de análise do impacto das tecnologias na educação e visualização destas como ferramentas no processo de ensino-aprendizagem, além da melhora da capacidade de compreensão do mundo das participantes, por meio dos ambientes tecnológicos disponíveis.

Essa mudança de mentalidade para uma prática mais inovadora pode ser explicada por $50 \%$ concordarem totalmente e $40 \%$ concordarem no reconhecimento de que os recursos tecnológicos digitais favorecem as aprendizagens múltiplas em um universo com pessoas com necessidades diversificadas e $40 \%$ concordarem e $40 \%$ concordarem totalmente que os alunos têm a necessidade de fazer uso em sala de aula de ferramentas tecnológicas digitais.

$\mathrm{O}$ reconhecimento citado acima contribui efetivamente para o enfoque dado às tecnologias digitais no projeto, tanto na parte teórica, quanto na parte prática, de que as tecnologias digitais podem colaborar para uma aprendizagem divertida e prazerosa, aproximando as vivências cotidianas dos alunos das vivências escolares, concordando totalmente com essa afirmação $50 \%$ e $40 \%$ concordando. Em consonância, $50 \%$ afirmaram concordar totalmente e $40 \%$ afirmaram apenas concordar que, ao utilizar as ferramentas tecnológicas digitais em sala de aula, percebem uma maior motivação e/ou interesse dos alunos pelo

Persp. online: hum. \& sociais aplicada., Campos dos Goytacazes, 19 (7), 48-53, 2017

seer.perspectivasonline.com.br 
conteúdo trabalhado. Vemos, aqui, o cumprimento do objetivo de resgate nas participantes, como professoras, do prazer pelo ensino, além da valorização profissional docente.

O desafio futuro é capacitar cada vez mais as alunas para essas práticas e colaborar para que evoluam no conhecimento sobre as TIC, de forma integral, para que utilizem, discursem e compartilhem conhecimentos sobre este tema, sendo replicadoras dos frutos do projeto.

Por ser o Educatec um projeto de iniciação científica, temos incentivado as alunas a fazerem reflexões teóricas para que, concomitantemente ao relato das experiências práticas, produzam artigos científicos.

\section{CONSIDERAÇÕES FINAIS}

Ao longo de todo o desenvolvimento do trabalho, entrelaçam-se a ressignificação de valores, crenças e teorias enraizados na prática docente frente ao uso dos recursos tecnológicos. O intuito do projeto Educatec é, a todo o tempo, mostrar outras condições que permitam a participação ativa das participantes professoras nos processos de definição de novos modos de ensino, dando direções inovadoras, mas comprometidas com a qualidade da educação (tanto pública, quanto privada) em Campos dos Goytacazes.

Para tanto, temos como meta alcançar esses resultados (que já estão em processo):

- Construir de forma coletiva e compartilhada materiais pedagógicos, facilitando o ensino com o uso dos recursos tecnológicos.

- Efetivar o uso de recursos tecnológicos no cotidiano escolar, para a melhoria do ensino e da escola.

- Elaborar artigos resultantes de relatos de experiência em sala de aula e apresentá-los em congressos e eventos científicos de extensão universitária.

- Dar condições às participantes do projeto de melhorar o desenvolvimento do seu trabalho na escola em que atua e facilitar a aprendizagem dos seus alunos, por meio de inovações pedagógicas instrumentalizadas pelos recursos tecnológicos no contexto escolar.

Ao final do projeto, pretendemos que as participantes sejam protagonistas de práticas inovadoras em sua atuação profissional, preocupando-se com o público-alvo a que se dirigem e com a superação das dificuldades pessoais e de seu contexto, indo além da simples aplicação de uma tecnologia em sala de aula. O nosso desejo é que o domínio de certas teorias sobre as tecnologias digitais e a clareza sobre a necessidade de buscar cada vez mais, por meio da pesquisa, inspire as participantes a um novo fazer pedagógico, oportunizando a cada uma delas lançar mão de todas as suas experiências diárias, mesclá-las com tudo que apreendeu e inovar.

\section{REFERÊNCIAS}

ALLAN, Luciana. Escola.com: como as novas tecnologias estão transformando a educação na prática. Barueri, SP: Figurati, 2015.

BAUMAN, Zygmunt. Modernidade líquida. 0. ed. [S.1.]: Jorge Zahar, 2001.

COX, Kenia Kodel. Informática na educação escolar. 2.ed. Campinas, SP: Autores Associados, 2008.

DWYER, David C.; RINGSTAFF, Cathy; SANDHOLTZ, Judith Haymore. Ensinando com tecnologia: criando salas de aula centradas nos alunos. 1. ed. [S.1.]: Artes Médicas, 1997.

KENSKI, Vani Moreira. Educação e tecnologias: o novo ritmo da informação. Campinas, SP: Papirus, 2007.

LÉVY, Pierre. A inteligência coletiva: por uma antropologia do ciberespaço. 4. ed. [S.1.]: Loyola, 2003.

34, 2004.

As tecnologias da inteligência: o futuro do pensamento na era da informática. 0. ed. [S.1.]:

Cibercultura. São Paulo: Editora 34, 1999.

O que é o virtual?. 1. ed. São Paulo: Editora 34, 1999.

MORAN, J. M. Novas tecnologias e mediação pedagógica. Campinas, SP: Papirus, 2000.

Persp. online: hum. \& sociais aplicada., Campos dos Goytacazes, 19 (7), 48-53, 2017

seer.perspectivasonline.com.br 
MORIN, Edgar. Introdução ao pensamento complexo. Trad. Eliane Lisboa. 5. ed. Porto Alegre: Sulina, 2015.

Os sete saberes necessários à educação do futuro. 3. ed. [S.1.]: Cortez, 2001.

POZO, J. I. O processamento de informação como programa de pesquisa. In: Teorias cognitivas da aprendizagem. Porto Alegre: Artes Médicas, 1998, p. 37-58.

, Humana mente: El mundo, La conciencia y La carne. Madrid: Mor, ata, 2003.

RECUERO, Raquel. . Redes sociais na internet. Col. Cibercultura. Porto Alegre:

Sulina, 2009.

SOUZA, Carlos Henrique Medeiros de. Comunicação, educação e novas tecnologias. 0. ed. [S.1.]: FAFIC, 2003.

. A Informática na Educação - Um caso de Emergência. Rio de Janeiro. Ed. DAMADÁ, 1999. 